\title{
Reportagem A difícil arte de gerir pessoas
}

Por Christiane Telles, especial para a RSP e Claudia A sazu

Adam Smith, em 1776, já chamava a atenção para o peso do trabalho na vida cotidiana e na saúde ou doença mental do trabalhador. $\mathrm{O}$ autor diz, em Riqueza das $\mathrm{N}$ açoes, que "(...) o homem que passa a vida realizando poucas operações simples torna-se tão estúpido e ignorante quanto é possível a uma criatura humana". A importância da dimensão humana nas organizações, por sua vez, foi sistematizada há mais de 90 anos nas pesquisas de Mary Parker Follett, com a publicação, em 1924, do livro Creative $\mathrm{E}$ x perience, que se contrapôs à lógica da "linha de montagem" de Ford. De lá para cá, muito foi aperfeiçoado em termos de gestão de pessoas em organizações privadas e públicas, mas essa área permanece sendo uma das mais delicadas. Nos últimos 20 anos, o foco passou da "gestão de recursos humanos" para a "gestão de pessoas", o que vem ocorrendo também no setor público. Trata-se de um modelo de gestão que prioriza a melhoria contínua por meio da capacitação e do comprometimento dos colaboradores. A ênfase da gestão, explica Joel Souza Dutra, professor da Faculdade de Economia e Administração da Universidade de São Paulo (FEA/ USP), deslocou-se do controle dos funcionários para o desenvolvimento mútuo. "D eve-se estar atento aos perfis dos profissionais Cada um dos funcionários tem habilidades, aptidões e desempenhos diferentes. G erir pessoas é estimular 0 envolvimento e o desenvolvimento delas", ressalta. Isso impõe, de outra parte, mais desafios às diretorias e coordenações de recursos humanos, de um lado, e aos chef es-gerentes, de outro. Um exemplo disso diz respeito a como lidar com 0 estresse ocupacional. Nesta edição, a RSP traz algumas experiências inovadoras de gestão de pessoas no setor público, como os programas da Presidência da República, da Radiobrás e da Caixa E conômica Federal, e finaliza tratando da questão do estresse resultante do trabalho.

\section{Q ualidade de vida, qualidade do trabalho}

Para suportar as demandas que ultrapassavam os limites das atribuições de praxe de um departamento de recursos humanos, como cuidar das contratações, férias e licenças, a área de recursos humanos da Presidência da República passou por uma reestruturação, cujo marco inicial foi elevação de seu status $O$ que antes se resumia a duas coordenações dentro da Diretoria de O rçamento e Finanças passou a ser a Diretoria de G estão de Pessoas. 
Segundo sua diretora, Selma Q uintella, o principal desafio ao iniciar a implementação da nova diretoria - responsável por 48 unidades e um universo de 5.725 servidores, sendo 1.672 só da Casa Civil -, foi fazer com que ela fosse estratégica, tendo como pilares a gestão de pessoas, do conhecimento, das competências e da informação. "Esse modelo de gestão é algo muito maior do que trabalhar recursos humanos, porque a pessoa tem de ser reconhecida em uma amplitude muito maior do que um recurso", explica Selma.

Todos os meses, a diretoria disponibiliza uma programação de atividades. Para manter essas ações, foram firmadas parcerias com 14 órgãos da Administração Pública Federal, o Pool de Capacitação, entre eles a ENAP, a Escola de Administração Fazendária (ESAF), o Banco do Brasil, o Centro de Desenvolvimento Científico e Tecnológico (CNPq) e a Petrobrás. De 2003 a junho deste ano, 5.720 funcionários foram beneficiados por esse programa. "Ao retornarem dos cursos e atividades, os servidores estão muito motivados, a mudança é fantástica. Eles têm uma ânsia muito grande para serem mais bem aproveitados. Temos até uma atividade chamada 'Fábrica de Idéias', em que as pessoas que retornam dos cursos apresentam sugestões e projetos, de acordo com que aprenderam de novo", conta Selma.

Também faz parte das ações da diretoria o programa de relacionamento com os órgãos de origem, pelo qual cada servidor que chega à Casa Civil ou à Presidência da República ganha um tutor, que é responsável por ambientar o novo colega. A reativação do setor de preparação física, onde são oferecidos fisioterapia e musculação, e o reaparelhamento do pronto atendimento médico-laboratorial também fazem parte dos planos da diretoria. "Nós estamos conseguindo resultados muito mais rápido do que esperávamos. 0 modelo deu certo e conseguimos dar um retorno positivo aos nossos servidores".

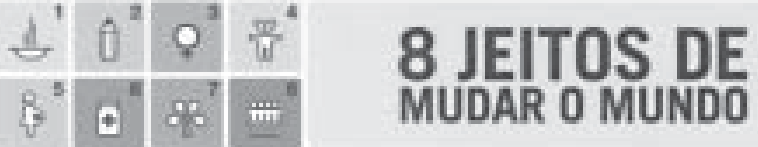

\section{De olho nos Objetivos do Milênio}

A Semana de Qualidade de Vida - V Pensa Vida, organizada pela Diretoria de Gestão de Pessoas da Presidência da República, foi uma maneira de engajar os servidores para os Objetivos de Desenvolvimento do Milênio, propostos pela Organização das Nações Unidas (ONU). Neste ano, a programação do V Pensa Vida deu ênfase aos sétimo objetivo: Qualidade de vida e respeito ao meio ambiente. A atividade deu início à implementação do projeto de educação ambiental na Presidência da República. A programação contou com a palestra da Ministra do Meio Ambiente, Marina Silva, exposições e com uma mostra de cinema ambiental.

Outra iniciativa do governo federal, do Programa das Nações Unidas para o Desenvolvimento (PNUD) e do Movimento Nacional pela Cidadania e Solidariedade é o Prêmio ODM Brasil 2005, que tem como objetivo divulgar as ações de prefeituras, organizações e pessoas/entidades de destaque que contribuam para a implementação dos ODMs no País. A cerimônia de premiação ocorrerá em dezembro. 
A servidora Katarina Freitas, da Casa Civil, concorda. "Já fiz vários cursos e sempre volto motivada e com novas propostas. A responsabilidade do servidor aumenta por estarmos mais capacitados para novas tarefas, desafios e projetos", enfatiza.

\section{Bem-estar}

Q uinta-feira, 23 de junho, 17 horas. É horário de expediente, mas os servidores da Presidência da República aproveitam a programação da Semana de Q ualidade de Vida da Presidência da República - V Pensa Vida, evento que incluiu a realização de palestras sobre saúde e meio-ambiente e a disponibilização de serviços de podólogas, cadeiras de relaxamento e sessões de massagem, entre outros. A servidora Silvia Aparecida Costa, da Coordenação-Geral de G estão de Informação, era uma delas. "É muito bom poder sair da rotina e fazer outras atividades. Isso mostra que a organização também se preocupa com o bemestar dos funcionários", disse.

\section{Convergindo interesses}

Reestruturar também foi o mote da mudança na gestão de pessoas na Radiobrás. "Tínhamos um cenário em que a organização não possuía visão coletiva do trabalho. 0 estilo pessoal se sobressaía, o que gerava conflitos", diz o diretor de G estão de Pessoas e Administração da Radiobrás, Henri Kobata. A idéia era implementar um modelo de gestão que atendesse tanto as necessidades dos servidores como as carências da empresa.

O programa começou a partir de uma pesquisa de grande escala com osservidores. Foram realizadas entrevistas pessoais com cerca de 200 pessoas - o que correspondia a 20\% da empresa - e a criação de 17 grupos de trabalho sobre os temas estratégicos da organização, entre os quais se encontravam, por exemplo, o desenvolvimento interno de gente, o plano de comunicação interna, o plano de cargos e salários e a avaliação de desempenho. De acordo com Kobata, houve uma grande mobilização dos funcionários para que, sob a orientação da equipe de educação e desenvolvimento, fossem discutidos os principais problemas e apontadas soluções para melhorar o trabalho. "É importante ressaltar que os funcionários participam voluntariamente desses grupos e, junto com os diretores, incluindo o presidente Eugênio Bucci, decidem os encaminhamentos dos pontos estratégicos", explica. Assim surgiu um novo estilo de gestão dos 1.185 servidores da Radiobrás. Em 2004, no 90 Concurso Inovação na Gestão Pública, realizado pela ENAP e pelo Ministério do Planejamento, a experiência da Radiobrás ficou em $4^{\circ}$ lugar.

"A nossa visão é fazer rádio, televisão e agência com foco no cidadão. Mas, para chegar a um nível de excelência, é necessário harmonizar o público interno pormeio da motivação e capacitação dos funcionários. Por isso desenvolvemos o Programa de Desenvolvimento de Pessoas, com 0 objetivo de convergir as necessidades e anseios do nosso quadro funcional às necessidades organizacionais", afirma.

\section{Integração maior}

"Eu participo do grupo de trabalho para a integração da fotografia com a Agência Brasil e posso afirmar que aumentou a interação entre as equipes. Esse programa trouxe motivação para os funcionários sim", relata Marcelo Casal, chefe do D epartamento de Fotografia da Radiobrás. Com 13 anos de casa, Marcelo diz que a criação dos grupos facilitou ter suas idéias e 
opiniões ouvidas. Em sua opinião, eles representam um espaço de participação em decisões de interesse geral como as referentes a salário e planos de carreiras. 0 fotógrafo avalia que 0 trabalho fica mais dinâmico e que conversar com os colegas é uma grande troca de experiências.

\section{Inclusão social}

"Quando eu comecei a trabalhar na Radiobrás, estava totalmente deslocada na parte administrativa, embora tivesse sido aprovada no concurso como publicitária. No meu caso, sou cadeirante, era mais difícil, pois o deslocamento era complicado. Antes de começar efetivamente a trabalhar, fiquei sete meses esperando em casa para que construíssem, na empresa, rampas de acesso e um banheiro adaptado", conta a jornalista e publicitária D anielle Lessa. Ela foi uma das primeiras beneficiadas pelo atual modelo de gestão. Teve, assim, a oportunidade de ser remanejada para uma função que considerou mais adequada no momento. "Eles me perguntaram onde eu gostaria de trabalhar e desde então sempre encontrei respaldo para ser remanejada. Trabalhei na Diretoria de G estão, na Assessoria da Presidência e no jornalismo", relata $\mathrm{D}$ anielle. A tualmente funcionária da Câmara dos Deputados, ela lembra com carinho dos tempos de Radiobrás. "Tenho uma relação forte, até mesmo afetiva, com a empresa, pois tive muitas oportunidades. Eles apostaram em mim e confiaram na minha capacidade", diz.

De acordo com Kobata, a ampliação de oportunidades é resultado de um trabalho com a consciência e a responsabilidade das pessoas. "Realizar pequenos cursos de capacitação, oferecer ginástica laboral - que inclusive sempre existiu - é só perfumaria", afirma.

\section{Alguns resultados do novo modelo na Radiobrás}

$\checkmark \quad$ Novo Plano de Cargos e Salários baseado em competências e no processo de tomada de decisões

$\checkmark \quad$ Um em cada dois empregados passou por treinamentos e cursos de desenvolvimento em 2.227 horas dedicadas ao crescimento pessoal e profissional

$\checkmark$ Programa de educação para a inserção de funcionários com transtorno bipolar e esquizofrenia, com limitações físicas e deficiência visual e dependentes de álcool

$\checkmark$ Avaliação de desempenho $360^{\circ}$

Assim, foi possível evitar um processo de exclusão dentro da Radiobrás "Não queremos que haja exclusão de nenhum tipo, seja em relação a um colega que demora mais tempo para terminar um texto, seja em relação ao que tem deficiência física ou que tem menos capacitação. 0 ideal é que as equipes sejam solidárias, trabalhem em conjunto e que aquele que sabe mais possa ensinar a quem sabe menos", enfatiza.

Foi dado início também um processo de transmissão de conhecimento entre os funcionários, por meio de cursos e treinamentos, com a participação dos grupos de trabalho. Servidores mais experientes começaram a ensinar os mais novos. Professores da Universidade de Brasília (UnB), da Universidade de São Paulo (USP) e os próprios diretores da Radiobrás foram os instrutores escalados para capacitar as equipes por meio de seminários ework shops. 


\section{Consolidando boas práticas}

As várias ações dedicadas à gestão de pessoas na Caixa Econômica Federal envolvem tanto os gestores como as equipes. "Temos convicção de que essa é uma das dimensões mais importantes para a criação e manutenção de um clima favorável à atuação de equipes comprometidas e motivadas para o desempenho de suas atividades", explica D iva deSouza Dias, diretora executiva de Recursos Humanos.

Para dar continuidade a essa linha de ação, a Caixa implementou a O ficina G estão de Pessoas, fundamentada no resultado do mapeamento de competências realizado pela empresa e na necessidade de consolidar o que vem dando resultados positivos. "A of icina foi estruturada por uma equipe interna, com

\section{0 que deu certo na Caixa}

$\checkmark$ Pesquisa de clima organizacional para implementação de ações focadas nas necessidades identificadas

$\checkmark$ Implantação do Programa de Qualidade de Vida, com ações de estímulo e incentivo à adoção e manutenção de hábitos saudáveis

$\checkmark$ Disponibilização de sistema de manifestação de interesse de realocação, que possibilita conciliar os interesses dos funcionários com os da empresa

$\checkmark$ Reestruturação da Universidade Corporativa, com a ampliação de oportunidades de desenvolvimento e especialização

$\checkmark$ Programas de bolsa, com ênfase na elevação do nível de escolaridade dos empregados o suporte metodológico de um consultor especializado, e implementada, em sua totalidade, por instrutores internos do quadro da Caixa".

Diva ressalta que a estrutura metodológica da oficina priorizou a criação de espaços para troca de conhecimentos e experiências em gestão de pessoas, a reflexão sobre as concepções de desenvolvimento humano, assim como a sua correlação com a prática de gestão de pessoas na empresa.

Durante o período de seis meses, de fevereiro a julho/ 2004, 12.084 gestores participaram das oficinas, nas quais foram também identificadas práticas bem sucedidas, consolidadas em um "Banco de Práticas", disponíveis para conhecimento, consulta e utilização por toda a empresa. Para essa ação, foram investidos R \$ 11,3 milhões, o que corresponde a $\mathrm{R} \$ 943,16$ por participante.

\section{Estresse no trabalho}

Manifestação de insatisfação, ansiedade, irritação, nervosismo, depressão, problemas na família e no desenvolvimento do trabalho são fortes indícios de estresse ocupacional.

É fundamental que os responsáveis pela gestão de pessoas estejam atentos ao tema porque o problema se reflete também nas organizações sob forma de absenteísmo, rotatividade de funcionários, diminuição de desempenho, acidentes no local de trabalho, por exemplo. É o que alerta a psicóloga Tatiane Paschoal, mestre em Psicologia Social e do Trabalho pela UnB.

Tatiane estudou o tema durante a elaboração de um instrumento de medição da escala de estresse no trabalho. Ela entrevistou 437 funcionários de empresas públicas e privadas do Distrito Federal e 
São Paulo, que responderam a um questionário composto por 23 itens, como:

- fico irritado por ser pouco valorizado por meus superiores;

- a falta de autonomia na execução do meu trabalho tem sido desgastante;

- as poucas perspectivas de crescimento na carreira têm me deixado angustiado.

0 resultado é uma espécie de fotografia sobre o nível de estresse e os motivos que levam o funcionário a essa doença, que oferecem orientação para as possibilidades de intervenção.

De acordo com a pesquisa, a média do estresse ocupacional nesta amostra foi de 2,5 numa escala de 1 a 5, o que significa que existem estressores, ou seja, situações e/ ou demandas de trabalho avaliadas negativamente pelos empregados, que poderiam ser modificadas para melhorar o bem-estar, mas a maioria dos trabalhadores ainda consegue lidar com eles. "Algumas pessoas apresentaram escores muito baixos, apontando que conseguem lidar bem com todas as situações de trabalho, e outras apresentaram índices bem altos, em torno de 4 na escala. Essas pessoas que percebem quase todas as situações de trabalho como estressoras precisariam de apoio especializado", ressalta Tatiane.

A aplicação do questionário em uma instituição bancária mostrou 0 seguinte cenário: 51 dos 237 respondentes apresentaram escore de estresse ocupacional entre 3 e 5. Estes percebem as situações de trabalho como mais estressoras e podem estar sofrendo um impacto nega tivo maior das condições de trabalho. Essa diferença acontece porque as demandas de trabalho são avaliadas diferentemente pelas pessoas. A mesma carga de trabalho pode ser vista como adequada por alguns ou como demasiada por outros. Assim, 61 respondentes também

\section{0 papel do chefe}

Q 0 chefe deve manter uma escuta ativa e estar aberto às sugestões dos seus subordinados

- Deve partir dele a iniciativa de entrar em contato com um psicólogo organizacional, para que seja feito o diagnóstico organizacional para seu setor, e depois, gerenciar a intervenção resultante do diagnóstico

Q 0 gerente tem o papel de liderar, gerenciar o processo de diagnóstico organizacional e intervenção (que deve contar com a presença de um psicólogo organizacional)

apresentaram estresse ocupacional bem baixo (entre 1 e 2), o que indica que conseguem lidar muito bem com todas as situações de trabalho.

Os principais estressores apontados pelos respondentes foram:

- sobrecarga de trabalho;

- deficiência na divulgação de informações sobre decisões organizacionais;

- relacionamento com o superior (por exemplo, tratamento recebido do superior na frente de colegas, etc.).

\section{Recomendações}

A psicóloga Tatiane Paschoal recomenda algumas intervenções que demandam a atuação daárea de gestão de pessoas e dos chefes e gerentes.

Uma delas é o apoio psicológico aos empregados com altos escores de estresse, de forma a auxiliá-los no desenvolvimento de habilidades para 0 enfrentamento dos estressores. A realização de atividades de relaxamento e práticas deatividade física por parte do empregado também são sugeridas. 
0 estresse ocupacional depende de situações do local de trabalho. Nesse sentido, a organização deve procurar diagnosticar o nível de estresse ocupacional de seus funcionários, identificar os principais estressores e intervir sobre elas. Essa intervenção pode ser, por exemplo, a adoção de programas claros de comunicação interna, com o objetivo de minimizar o impacto negativo que a deficiência na divulgação das decisões organizacionais tem sobre os funcionários.

Um outro exemplo diz respeito a treinamentos destinados a empregados que percebem que suas habilidades estão abaixo do necessário para realização das suas tarefas.
Tatiane frisa que aqueles que ocupam cargos de chefia devem estar atentos ao comportamento dos servidores. Um diretor-geral de uma empresa, por exemplo, não vai saber o que está acontecendo em todos os setores. Por isso, esse é um tipo de suporte que os gerentes podem oferecer a seus subordinados. "Os estressores organizacionais podem ser específicos para cada unidade. A intervenção, portanto, deve ser feita por setores ou departamentos. $\mathrm{E}$ é o chefe de cada unidade que deve ter a iniciativa de intervir sobre os problemas. Como ele está mais próximo dos seus funcionários, será o primeiro a perceber comportamentos ou atitudes disfuncionais dos seus subordinados". 


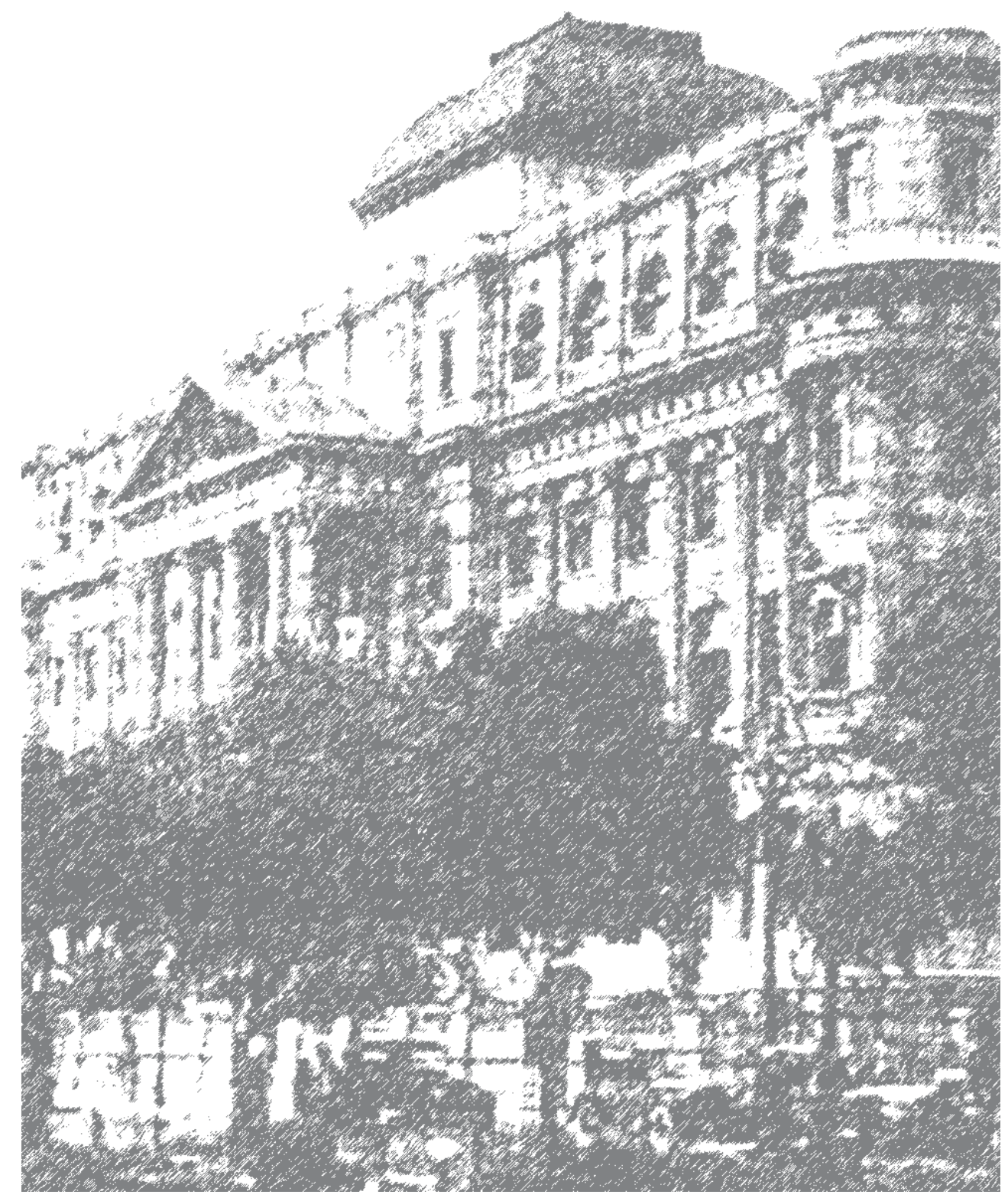

